\title{
PENSAMENTO CIVIL BRASILEIRO: ANÁLISE DA GENUINIDADE DO DIREITO EM TEIXEIRA DE FREITAS
}

Sílvia Helena Schimidt ${ }^{1}$ Allan Carlos Schimidt*

RESUMO: Pelo presente artigo científico apresenta-se um estudo sobre as principais ideias do jurista Augusto Teixeira de Freitas. O escopo da pesquisa é demonstrar se há originalidade no pensamento do referido jurista brasileiro, ou seja, se é possível identificar institutos do direito civil que foram criados por Teixeira de Freitas. A metodologia de abordagem é analítica e crítica, parte da análise de conceitos jurídicos estabelecidos no material normativo e doutrinário e segue para verificação de adequação dos conceitos operacionais. Nesse contexto, desenvolve crítica argumentativa pertinente ao pensamento civil brasileiro.

PALAVRAS-CHAVE: Pensamento Civil Brasileiro. Originalidade. Teixeira de Freitas. Direito Civil. História do Direito.

\section{BRAZILIAN CIVIL THOUGHT: ANALYSIS OF LAW GENUINENESS IN TEIXEIRA DE FREITAS}

\begin{abstract}
For the present scientific article a study is presented on the main ideas of the jurist Augusto Teixeira de Freitas. The scope of the research is to demonstrate if there is originality in the thought of said Brazilian jurist, that is, if it is possible to identify institutes of civil law that were created by Teixeira de Freitas. The approach methodology is analytical and critical, part of the analysis of legal concepts established in normative and doctrinal material and follows to verify adequacy of operational concepts. In this context, it develops argumentative criticism relevant to Brazilian civilian thought.
\end{abstract}

KEYWORDS: Brazilian Civil Thought . Originality. Teixeira de Freitas. Civil right. History of Law.

\footnotetext{
* Bacharel em Direito pela Universidade de Ciências Sociais Aplicadas de Sinop - ÚNIC; Pós graduada em Direito de família e das Sucessões e Direito Imobiliário pela Universidade Anhanguera; Mestranda em Direito pela CESUMAR. Tabeliã e Registradora no Estado do Maranhão. E-mail: advsilvia1@hotmail.com. Endereço postal: Rua do meio, 46 - centro - Peritoró MA

* Bacharel em Direito pela Faculdade de Sinop - FASIPE; Pós graduado em Direito Civil e Direito Processual Civil pela Faculdade de Sinop - FASIPE; Advogado militante; E-mail: advschimidt@gmail.com. Endereço postal: Av. dos Ingás, 2107 Sala 2 Jardim Maringá I Sinop MT.
} 


\section{INTRODUÇÃO}

Existe um pensamento civil brasileiro? O ordenamento jurídico brasileiro, no âmbito do direito civil, surge somente de institutos internacionais inseridos no sistema normativo pátrio ou é possível detectar originalidade em algum princípio, regra ou teoria de direito civil estabelecido no Brasil? A resposta a essas perguntas é um dos objetivos da presente pesquisa, busca-se, assim, analisar elementos do direito civil brasileiro, especificamente nas obras do grande jurista brasileiro, Teixeira de Freitas, para verificar a singularidade, ou seja, se nascem de ideologias da identidade nacional, fruto do desenvolvimento intelectual autônomo dos juristas brasileiros ou se são simples cópia, mera transcrição com alguma modificação do pensamento de juristas de outros países.

A presente investigação, mais que descritiva de regras e princípios de direito civil revisita a história do direito civil no Brasil, estuda o surgimento e a evolução das regras e princípios de direito privado em solo brasileiro. Examina, portanto, a essência, as origens e os idealizadores do ordenamento jurídico brasileiro, no aspecto do direito civil, no intuito de assimilar cientificamente seu conteúdo e extrair alguma base cognoscente de um raciocínio civilista eminentemente brasileiro.

A escolha de Teixeira de Freitas foi feita em razão de ser o jurista que estudou o direito privado como ciência e que foi responsável pela consolidação de todas as normas de direito civil aplicáveis ao direito brasileiro, bem como por ser reconhecido como um dos primeiros cientistas do direito brasileiro, que teve por atribuição específica criar um sistema brasileiro de direito civil.

\section{O SURGIMENTO DO DIREITO CIVIL NO BRASIL}

A busca pela concretização da colonização portuguesa a partir do ano de 1500 revela que os primeiros traços jurídicos que surgem no Brasil são de natureza privada, pois decorrem do caráter contratual do direito estabelecido. O primeiro instituto que demonstra esta constatação, conforme Nascimento (1999, p. 192) é o contrato de arrendamento celebrado por

Revista Brasileira de Direito Civil em Perspectiva | e-ISSN: 2526-0243 | Salvador | v. 4 | n. 1 | p. 18 - 38 | Jan/Jun. 2018 


\section{PENSAMENTO CIVIL BRASILEIRO: ANÁLISE DA GENUINIDADE DO DIREITO EM TEIXEIRA DE FREITAS}

D. Manoel I com a sociedade de mercadores representada por Fernão de Noronha, segundo o qual os contratantes, durante o prazo de três anos, obrigavam-se a enviar anualmente ao Brasil o número de seis navios, bem como "procederem ao reconhecimento de trezentas léguas de terra e de fundar e manter fortaleza.”

No mesmo sentido, verifica-se que o nascimento das normas administrativas do território brasileiro também tem como base institutos de natureza privada, com suporte principiológico estabelecido pelo direito civil. Nesse modo, é o corpo normativo que investe Martin Afonso de Souza com amplos e excepcionais poderes para instalar o embrião da administração pública no Brasil, que se dá pelas três cartas régias ${ }^{2}$ de D João III, no ano de 1530. A primeira carta régia atribui a Martin Afonso a qualidade de capitão-mor, com poderes jurisdicionais cíveis e criminais para decidir inclusive sobre a vida e a morte de todas as pessoas que habitassem o solo brasileiro; a segunda carta régia destina poderes para criação e nomeação de tabeliães e demais auxiliares das “cousas da justiça e governança” (FREITAS, 1924, P. 27); a terceira carta régia confere ao capitão-mor o poder de entregar terras por sesmaria, utilizando critérios de merecimento por serviços prestados e pela qualidade no aproveitamento das terras brasileiras.

Seguindo-se a análise histórica do surgimento do direito brasileiro, ainda no período colonial, merece destaque a análise de dois outros institutos, também de natureza privada: as cartas régias de doação e o foral, que iniciam o período das capitanias hereditárias. A capitania era doada pelo Rei de Portugal que transmitia a posse direta da terra e alguns poderes inerentes à própria Coroa Real Portuguesa, permitindo-se o exercício privado da exploração sem afastar a soberania de Portugal sobre o território brasileiro. Os forais, de outro lado, vinculados à emissão da carta régia de doação da capitania, estabeleciam a forma e percentual de cobrança de tributos. Nessa esteira, Fleiuss (1925, p. 8) afirma que o sistema de capitanias hereditárias vigeu de 1534 a 1548 e dividia o território brasileiro em 15 lotes de trinta a cinquenta léguas de costa, que formavam 12 capitanias hereditárias, distribuídas a 13 portugueses.

\footnotetext{
2 Segundo Rui de Figueiredo Marcos, Carlos Fernando Mathias e Ibsen Noronha (2014, p. 131) as cartas régias foram dadas em Castro Verde, em 20 de dezembro de 1530 e encontra-se registradas no livro 41, da Chancelaria de D. João III, fls. 103 e 105.
}

Revista Brasileira de Direito Civil em Perspectiva | e-ISSN: 2526-0243 | Salvador | v. 4 | n. 1 | p. 18 - 38 | Jan/Jun. 2018 
Dessa forma, os capitães donatários, pelas cartas régias de doação da capitania, estabeleciam as sesmarias, instituto jurídico português que foi responsável pelo surgimento do latifúndio nas terras brasileiras. A corroborar o exposto, insta transcrever a reflexão de Liberato (2003, p. 21) que assim preleciona: "Houve a implementação de um verdadeiro sistema feudal, fora da Europa e em uma época onde este já havia se desintegrado”. No mesmo aspecto é Coggiola (1999, p. 53) segundo o qual: “Nascia a propriedade privada então revestida das características jurídicas de doação oficial e governamental. O latifúndio, tipo fazenda, estava criado.”

Em outra vertente, a primeira norma de caráter público, inclusive de natureza hierárquica superior às normas de direito civil antemencionadas, é o Regimento de 17 de dezembro de 1548, que cria o sistema de Governo Geral no território brasileiro. Esse modelo não extingue diretamente as capitanias hereditárias, no entanto, estabelece um intermediário, com poderes centralizados, entre a Coroa Portuguesa e os donatários hereditários. No entendimento de Calmon (1943, p. 12) o Regimento de 1548 pode ser considerado a primeira Constituição do Brasil.

\section{OS PRIMEIROS JURISTAS BRASILEIROS}

Esta investigação parte da formação intelectual de um jurista brasileiro que teve suas bases formadas nas duas escolas jurídicas no Brasil. Entretanto, mesmo que o objeto de estudo desta pesquisa seja o pensamento de um único jurista brasileiro, não se afirma inexistência de pensamento jurídico brasileiro em período anterior, bem como não se nega a existência de diversos outros juristas com pensamento de relevante contribuição para o direito civil brasileiro. A opção por estudar a intelectualidade de Teixeira de Freitas é, portanto, metodológica, busca avaliar o pensamento deste civilista que surge nas academias brasileiras, entretanto, não se descarta o reconhecimento de diversos pensadores do direito no período colonial e imperial.

Pela observação dos pensadores brasileiros e portugueses durante este período é possível identificar diversos intelectuais: o Padre Antônio Vieira, por exemplo, escreveu mais de mais de 200 sermões, 700 cartas, tratados proféticos, relações etc e abordava diversos aspectos jurídicos do Brasil colonial. Os egressos de Coimbra: Cláudio Manoel da Costa, José

Revista Brasileira de Direito Civil em Perspectiva | e-ISSN: 2526-0243 | Salvador | v. 4 | n. 1 | p. 18 - 38 | Jan/Jun. 2018 
Inácio de Alvarenga Peixoto, Tomás António Gonzaga e José Alves Maciel, mentores da inconfidência mineira, conforme Castro (2007, p. 111) influenciam sobremaneira o surgimento de um novo pensamento sobre o Brasil em diversos aspectos, incluindo-se o direito.

No âmbito acadêmico, conforme ensina Calmon (1982, p.93), merecem destaque: João Pereira Ramos de Azeredo Coutinho e seu irmão Francisco de Lemos de Faria Pereira Coutinho, ambos nascidos no Rio de Janeiro e responsáveis pela reforma dos Estatutos Pombalinos da Universidade de Coimbra.

Na indicação de pensadores influentes da área do direito neste período, não se pode deixar de destacar a ideologia de José Bonifácio de Andrada e Silva, patriarca da independência do Brasil, ilustrado aqui na categoria de diversos brasileiros que frequentavam a Faculdade de Cânones e a Faculdade de Leis, conforme ensina Rodrigues (2007, p. 857)

Cabe destacar, que entre os diversos juristas que tiveram sua formação nas duas primeiras faculdades de Direito do Brasil, Olinda/Recife e São Paulo, cita-se, apenas por ilustração, pois não serão objeto de estudo na presente investigação, os seguintes pensadores: Eusébio de Queirós, José Tomás Nabuco de Araújo (pai de Joaquim Nabuco), Cândido Mendes de Almeida, Antônio Pinto Nogueira Acioly, Sigismundo Gonçalves, Tobias Barreto, Joaquim Nabuco, José Mariano, Ulysses Vianna, Bandeira de Melo, J. J. Seabra, Clóvis Beviláqua, Epitácio Pessoa, Graça Aranha, Eugênio de Barros, Nilo Peçanha, todos da Faculdade de Olinda/Recife. Na mesma análise, mas com formação na Faculdade de Direito de São Paulo, destacam-se os seguintes pensadores: Ruy Barbosa (que iniciou o curso em Recife e terminou na Faculdade de São Paulo), Álvares de Azevedo, Campos Sales, Rodrigues Alves, Prudente de Moraes, Bernardo Guimarães, Nilo Peçanha e outros.

$\mathrm{Na}$ proposta que ora se delineia, é possível afirmar a existência de diversas manifestações e pensadores que se destacaram na área jurídica em período anterior e após o lapso temporal investigado na presente pesquisa, que poderão ser objeto de outras análises no sentido de confirmar ou refutar a hipótese de existência de um pensamento civilista brasileiro neste período histórico da sociedade brasileira, a saber, no período colonial e no início do período imperial, anterior ou após a criação dos primeiros cursos jurídicos no Brasil.

\subsection{A Criação dos Primeiros Cursos Jurídicos no Brasil}

Revista Brasileira de Direito Civil em Perspectiva | e-ISSN: 2526-0243 | Salvador | v. 4 | n. 1 | p. 18 - 38 | Jan/Jun. 2018 
O Artigo 139, XXXIII, da Constituição Imperial de 1824, estabelece que a inviolabilidade dos direitos civis, a liberdade, a segurança individual e a propriedade são garantidas, dentre outras formas, pela criação de: "Collegios, e Universidades, aonde serão ensinados os elementos das "Sciencias, Bellas Letras, e Artes.” (BRASIL, 1824) Nessa vertente, para dar concretização à referida norma constitucional, no âmbito da ciência do direito, criam-se, em 11 de agosto de 1827 os dois primeiros cursos jurídicos do Brasil: "Curso de Sciencias Jurídicas e Sociaes” um na cidade de São Paulo e outro na Cidade de Olinda em Pernambuco.

A discussão legislativa sobre a criação dos dois cursos jurídicos tem início no projeto de lei de 19 de agosto 1823, que aplicaria às universidades que seriam criadas em São Paulo e Olinda os estatutos de ensino da Universidade de Coimbra. A indicação da cidade de São Paulo foi objeto de muita discussão entre os parlamentares, destacando-se Carvalho e Mello, futuro Visconde da Cachoeira e Francisco da Silva Lisboa, fundador e primeiro presidente do Instituto dos Advogados do Brasil e futuro Visconde de Cairu, bem como, Francisco Gomes Brandão, Visconde de Jequitinhonha ${ }^{3}$, que defendiam a instalação da universidade na cidade do Rio de Janeiro. O projeto, entretanto, não foi promulgado, haja vista a dissolução do parlamento em 1823.

Em 11 de agosto de 1828 o novo projeto de lei que cria os dois cursos jurídicos, um em São Paulo e outro em Olinda, é convertido em Lei. O funcionamento efetivo da Faculdade de Direito de São Paulo, conforme leciona Nogueira (1953, p. 35 e 56), ocorreu no dia $1^{\circ}$ de março de 1828, no Convento dos Franciscanos, com a primeira aula ministrada pelo Dr. Brotero. A Faculdade de Olinda, instalada primeiramente no Convento Beneditino e dirigida por Lourenço José Ribeiro (depois nomeado Ministro do Supremo Tribunal de Justiça em 1832), teve sua primeira aula ministrada em 2 de junho de 1828. Importante mencionar que a Faculdade de Olinda aceitava a matrícula de estrangeiros, o melhor exemplo é Eusébio de Queiroz, angolano, primeiro lugar nos exames de admissão, que em 1848, na qualidade de Ministro da Justiça edita

\footnotetext{
${ }^{3}$ Francisco Gomes Brandão alterou o nome para Francisco Gê Acayaba de Montezuma, recusou o título de Barão de Cacheira, mas em 1854, aceitou o título de Visconde de Jequitinhonha.
} 


\section{PENSAMENTO CIVIL BRASILEIRO: ANÁLISE DA GENUINIDADE DO DIREITO EM}

TEIXEIRA DE FREITAS

a lei que proíbe o tráfico de escravos no Brasil, que ficou conhecida com Lei Eusébio de Queiroz.

O ensino do direito, em ambas as Faculdades, ao longo de cinco anos, abrangia: direito natural, análise da Constituição do império, direito das gentes e diplomacia, no primeiro ano; no segundo ano, além da continuação das matérias do ano anterior, acrescentava-se o direito eclesiástico; direito civil pátrio, direito criminal pátrio e processo criminal, eram matérias do terceiro ano; no quarto ano continuava-se a disciplina de direito civil pátrio e acrescentava-se o direito mercantil e marítimo; por fim, no quinto e último ano, os já quase bacharéis estudavam economia política e teoria e prática processual das leis do império. É com essas bases disciplinares que surgem os pensadores do direito e também Teixeira de Freitas, que passaremos a analisar para verificar a existência de um pensamento genuinamente brasileiro no âmbito do direito civil.

\section{TEIXEIRA DE FREITAS}

Escolher um único pensador para avaliar a existência de um pensamento civilista brasileiro não é tarefa de fácil resolução, pois correr-se o risco de não analisar pensadores que muito contribuíram para a evolução da ciência do direito no Brasil. Entretanto, procurando a isenção que merece uma pesquisa científica na presente investigação optou-se pela a análise do pensamento de Teixeira de Freitas, pelo fato peculiar, não encontrado em diversos outros pesquisadores, de ter ele estudado em ambas as Faculdades, Olinda e São Paulo. Nesse passo, é possível analisar as ideias de um jurista que foi influenciado pelas duas maiores correntes do pensamento jurídico no período Imperial e no limiar da República.

Augusto Teixeira de Freitas ingressa como aluno no curso de direito da Faculdade de Olinda no início do ano de 1830 e no mesmo ano pede transferência para a Faculdade de São Paulo. Por desavenças com professores, retorna a Olinda onde termina o curso em 1837.

Segundo Marcos; Mathias; Noronha (2014, p. 315) pelo seu destaque como jurista, em 1855 é contratado pelo governo imperial de D. Pedro II para a elaboração de uma consolidação da legislação civil brasileira. Antes do prazo determinado pelo Imperador, a Consolidação da

Revista Brasileira de Direito Civil em Perspectiva | e-ISSN: 2526-0243 | Salvador | v. 4 | n. 1 | p. 18 - 38 | Jan/Jun. 2018 
Leis Civis Brasileiras foi entregue pelo autor e aprovada por uma comissão de juristas do Poder Legislativo em dezembro de 1858.

Sobre a difícil tarefa de Teixeira de Freitas ao aceitar fazer a Consolidação das Leis Civis do Brasil é Santos (2003, p.358): “Por essa proposição, é possível verificar que o trabalho era hercúleo. Somente um espírito atilado e pouco afeito à vida em sociedade, personalidade forjada no estudo solitário, poderia aceitar tamanha incumbência. A magnitude e a dificuldade da obra que deveria ser empreendida mostram que o trabalho não poderia ser efetuado por qualquer um.”

Em seguida, o jurista elabora o que a doutrina denomina "Esboço" de Teixeira de Freitas, mas que não teve a mesma sorte de sua Consolidação, pois a Comissão que iria o trabalho do jurista brasileiro foi extinta para se evitar, em tese, a desmoralização intelectual do autor com a quase certa rejeição do "Esboço”. A Comissão de análise do “Esboço” foi formada inicialmente pelo: Visconde do Uruguai; Nabuco de Araújo (que era amigo de Teixeira de Freitas e um dos responsáveis pela extinção da Comissão, antes da rejeição do “Esboço”, que já era prevista por todos); Caetano Alberto Soares, relator; Antônio Joaquim Ribas, lente da Academia de Direito de São Paulo; Braz Florentino Henrique de Souza, da Academia do Recife, José Mariani, ministro do Supremo Tribunal de Justiça, Lourenço José Ribeiro, primeiro diretor interino do Curso de Olinda e desembargador da Redação da Corte; Francisco José Furtado, conselheiro e ex-ministro de Estado e Jerônimo Martiniano Figueira de Melo, conforme leciona Pedrosa (2006, p. 340).

Após o fracasso do “Esboço”, consoante Meira (1979, p. 515) Teixeira de Freitas muda-se para Niterói no Estado do Rio de Janeiro, local em que vem a falecer, após um período de muita infelicidade em sua vida:

Quis o destino que, com a transferência do domicílio para Niterói, estivesse Freitas escolhendo o lugar de seu último repouso. Nem Cachoeira, onde nascera, nem São Paulo e Olinda, onde estudara, nem Curitiba e Rio de Janeiro, onde vivera, arrebatariam essa glória. Seu falecimento não teve grande repercussão nos meios culturais e oficiais do país, na época. A Corte o desconheceu. Notícias lacônicas dos jornais, a mando da família, comunicavam o evento.

Cabe destacar, que mesmo não avançando no Brasil, o "Esboço” de Teixeira de Freitas, de algum modo, triunfou em outros países, servindo de base legal para o desenvolvimento da legislação privada da Argentina, pela genialidade da obra e pelo relacionamento de Teixeira 
de Freitas com o codificador argentino Dalmácio Vélez Sárfield. Para Meira (1983, p.71) o “Esboço” de Teixeira de Freitas influenciou, não só o direito civil dos países latinoamericanos, como Argentina, Uruguai, Paraguai, Nicarágua, mas o ordenamento jurídico privado de países da Europa, como Alemanha, Suíça, Itália e até mesmo países do Oriente, como Japão e China.

\section{A ORIGINALIDADE DO DIREITO CIVIL EM TEIXEIRA DE FREITAS}

No que se refere a presente investigação, bem como para entender a importância e possível originalidade do pensamento de Teixeira de Freitas, faz-se necessário um estudo, ainda que breve, sobre as principais normas de direito civil que inauguram o período de codificação do direito privado, o Código Civil Francês de 1804 e o Código Civil Alemão (Bürgerliches Gesetzbuch - BGB) de 1869. Outro fator importante para a compreensão do pensamento do jurista brasileiro é verificar sua principal influência, Savigny, que conforme Beviláqua (1930, p. 126): "Nenhum autor, porém, mereceu de Teixeira de Freitas maior simpatia do que Savigny, cujo nome aparece invocado 22 vezes na Introdução da Consolidação, ao passo que Mackeldey e Marezoll não o são mais de 12 vezes, Troplong e Martou, 9”.

O Código Civil Francês, inspirado pelo Imperador Napoleão Bonaparte, foi redigido no prazo de apenas três meses por Tronchet (Presidente da Cour de Cassation), Portalis (membro do Tribunal de Presas, Advogado e excelente jurista), Bigot de Préameneu (Comissário do Governo Junto ao Tribunal de Cassation) e Maleville (Juiz da Cour de Cassation). O referido diploma normativo, foi elaborado com a presença intensa do Imperador, pois teve cinquenta e cinco das cento e sete Comissões de Legislação do Conselho de Estado presididas pelo próprio Imperador Napoleão Bonaparte.

A referida codificação consegue unificar, em um mesmo conjunto de normas, leis que regulamentavam as mais diversas relações entre os cidadãos, uma organização normativa desenvolvida em torno do indivíduo. O Código Civil Francês ou Código de Napoleão teve com base os seguintes institutos: propriedade, contrato e responsabilidade civil, com normas que regulamentam as relações humanas desde o nascimento até a morte. A propriedade, com inspiração na Declaração dos Direitos Humanos de 1789 é elevada a um direito sagrado e 
inviolável e alguns institutos são consolidados pela primeira vez em um ordenamento jurídico, como é o caso do casamento civil.

O prestígio do referido Código é reconhecido ao verificar-se que dos mais de 2.302 artigos da versão original, mais de 1.200 continuam em vigor nos dias atuais é, desse modo, um referencial para todas as culturas jurídicas, em especial no âmbito do direito privado. Segundo preleciona Gómez (2004, p. 19): “sua sobrevivência histórica é um convite par refletir sobre sua dimensão simbólica, sobre sua influência como modelo jurídico e sobre os valores fundamentais da civilização que encarna, pois o Código Civil sempre foi instrumento de afirmação de direitos e de valores aos quais numerosos países reconheceram caráter universal”.

É de destacar-se ainda, que uma das principais inovações do Código Civil Francês foi a separação entre Direito Comercial e Direito Civil. Entretanto, conforme ensina Reale (2001, p. 364) este pensamento de unificação é fruto da genialidade e originalidade de Teixeira de Freitas:

\begin{abstract}
Alguns autores entenderam, já no século passado, que a distinção entre Código Civil e Comercial não tem mais razão de ser. O primeiro a afirmar a necessidade da unificação do Direito Privado foi o nosso Teixeira de Freitas. Recebeu ele a incumbência do Império de elaborar um Projeto de Código Civil. Depois de vários anos de indagações e pesquisas, o ilustre mestre, quando já havia redigido nada menos de 4.908 artigos de seu monumental "Esboço de Código Civil", declarou haver chegado à conclusão de que as obrigações civis e mercantis deviam ser disciplinadas num só Código, precedido de um Código Geral. Não obtendo o apoio do Governo para essa nova orientação, declinou ele da alta incumbência que lhe fora confiada.
\end{abstract}

A ratificar a afirmação anterior, sobre a criação jurídica de Teixeira de Freitas no que tange à visão orgânica do direito civil, em uma época em que não se havia o conceito definido de ordenamento jurídico, é Saldanha (1985, p. 247) segundo o qual: “A “genialidade”, que tantos têm apontado em sua obra, correspondeu a esta visão “orgânica” que possuiu para a imagem do direito legislado como um todo - , em época onde ainda não se dispunha do conceito de ordenamento; correspondeu também à sua extrema acuidade crítica, que era correlata de sua independência doutrinária, limítrofe de irreverência e congênere da ‘audácia’ [...]”

Revista Brasileira de Direito Civil em Perspectiva | e-ISSN: 2526-0243 | Salvador | v. 4 | n. 1 | p. 18 - 38 | Jan/Jun. 2018 
Na mesma linha de raciocínio, verifica-se que o jurista brasileiro estudava a possibilidade de aproximação de um sistema de direito civil brasileiro com inspiração no direito romano, haja vista pretender incluir no Código Civil diversos institutos do direito comercial: “Tal é o plano, que nos permitirá erigir um monumento glorioso, plantar as verdadeiras bases da codificação, prestar à ciência um serviço assinalado. Só ele corrigirá o vício que quase todos os trabalhos legislativos, que é o de tomar a parte pelo todo, o que frequentemente se faz por tudo que se pode fazer.

A esse propósito, mister trazer à lume o entendimento de Miranda (1954, p. 22) sobre Teixeira de Freitas, que afirmava tratar-se de uma inovação, sua teoria sobre a unificação do direito privado, bem como tecia críticas severas à não aceitação de tal tese no direito brasileiro vigente:

A ciência do direito, colhendo das regras jurídicas, da sistemática e da prática dos conceitos, obedece às diferenças; os juristas, aqui e ali, perdem-nas de vista. Tudo aconselha a que se ordenem as matérias com toda a precisão conceitual. Já Teixeira de Freitas perceberá que a parte do direito concernente à eficácia ('dos efeitos civis’ dizia ele) havia de ser todo um livro, após as causas, as pessoas, os bens e os fatos jurídicos. Somente depois se trataria no plano do direito civil - dos direitos pessoais e dos reais. O Código Comercial fundir-se-ia, unificando-se o direito privado. Foi isso que ele propôs em ofício de 20 de setembro de 1867, antes do Código suíço das Obrigações, - e a mediocridade circundante rejeitou.

Nessa esma vertente de entendimento é Câmara (1965, p. 146) ao afirmar que:

[...] nessa Tábua Sintética mantém ele a genérica divisão dos direitos em pessoais e reais, entre êstes incluindo a posse. Contudo, nas suas linhas gerais, não se afasta das idéias mestras já anteriormente consagradas na Introdução, de que, aliás, nunca se afastou. Isso vem confirmar a maturidade, a meditação, o estudo profundo dos quais resultou aquela classificação genial, infelizmente ignorada ainda tantos anos decorridos. 
Sobre a relação entre Teixeira de Freitas e Savigny é esclarecedor o ensinamento de Alves (1993, p. 200)

[...] em dois pontos se adiantava Freitas a Savigny: primeiro, porque este, ao aludir aos atos jurídicos que não eram negócios jurídicos, enquadrava neles atos lícitos e atos ilícitos; segundo, porque, enquanto Savigny apenas fazia a distinção, Freitas ressaltava claramente que os efeitos desses atos lícitos seriam somente os previstos na lei, o que só veio a ser evidenciado pela doutrina mais moderna, a partir do início do século XX, com Manigk, ao basear a distinção entre negócios jurídicos e participações de vontade na diferença entre efeitos ex voluntate e efeitos ex lege. Ë admirável, no plano estrito do legislador, a intuição de Freitas em incluir no Esboço esse art. 436. Só recentemente, em 1967, é que o novo Código Civil português veio a ocupar-se deles, preocupando-se, porém, apenas a alertar que a tais atos são aplicáveis, na medida em que a analogia das situações o justifique, as normas do negócio jurídico.

Em outra vertente de investigação, verifica-se que o Código Civil Alemão (Bürgerliches Gesetzbuch - BGB) de 1869 também influenciou sobremaneira o direito civil brasileiro, o que se comprava pelo elevado número de citações e remissões do referido estatuto de direito privado alemão nas obras de direito civil no Brasil. Sílvio Venosa em seu livro de direito civil cita o Código Alemão 21 (vinte e uma) vezes (VENOSA, 2013, p. 72, 82, 91, 94, 95, 96, 97, 102, 147, 198, 218, 239, 283, 308, 315, 364, 368, 413 e 447); Caio Mário da Silva Pereira em Instituições de Direito Civil faz 16 (dezesseis) remissões a artigos do Bürgerliches Gesetzbuch (PEREIRA, 2013, p. 71, 72, 122, 198, 243, 251, 317, 353, 364, 422, 423, 435, 449, 533, 552 e 564); Orlando Gomes, em seu livro de Introdução do Direito Civil menciona o BGB em 10 seções de sua obra (GOMES, 2010, p. 35, 36, 47, 70, 151, 175, 263, 267 e 302).

Convém lembrar, entretanto, que o Bürgerliches Gesetzbuch tinha como principal elemento de identificação a divisão do Código em Parte Geral e Parte Especial. Teixeira de Freitas, em divergência com a maioria dos estudiosos do direito civil de sua época, ao elaborar a consolidação e seu "esboço”, afastou-se das orientações principiológicas do direito civil 
francês e já estabelecia, de forma inédita, a necessidade de divisão do Código em parte geral e parte especial, nesse sentido é Capanema (2004, 36):

No período pré-codificado, em que entre nós vigoravam ainda as Ordenações Filipinas, e mesmo no magistral "Esboço" de Teixeira de Freitas, não se pode dizer que o direito brasileiro gravitava, como tantos outros, em torno do Código Napoleão. Muito ao contrário, Freitas criticava e se afastava da doutrina francesa, insurgindo-se contra a separação do Direito Comercial e o Direito Civil.

Merece destaque, nessa linha de estudo, que a divisão do Código Civil em parte geral e parte especial, amplamente divulgada pelo Código Civil Alemão de 1869, e depois adotada por quase todas as legislações civis todo o mundo moderno, já havia sido pensada pelo jurista brasileiro dez anos antes da entrada em vigor do Bürgerliches Gesetzbuch. A esse propósito, faz-se mister trazer à colação a acepção de Davis (2002, p. 108) segundo o qual foi Teixeira de Freitas quem, primeiro no mundo, teve a idéia de fazer distribuírem-se as matérias compendiadas num código civil, em parte geral e especial, antecipando neste ponto à legislação privada alemã. No mesmo sentido e corroborando o expendido acima é Câmara (1965, p.162): "tão propenso às especulações e sistematizações e que mais tarde, indiretamente, sem o saber, o tomara como espécie de paradigma [...].”

Outro instituto do direito civil, que tem novidade trazida pelo desenvolvimento intelectual de Teixeira de Freitas é dar forma jurídica à mobilização do solo pelo crédito, ou seja, com a criação dos fundos imobiliários e da securitização, o autor brasileiro inaugura, dessa maneira, o que depois é denominado direito bancário, desenvolvido somente no século XXI. Nessa vertente, é Wald (2004, p. 254-255) “Teixeira de Freitas teve a intuição de dar forma jurídica à mobilização do solo pelo crédito. Previu, assim, a existência do direito bancário, quiçá dos fundos imobiliários e da securitização, que surgiriam no Brasil no fim do século XX, desenvolvendo seno início do século XXI.”

Sobre o pensamento de Teixeira de Freitas, não se pode deixar de destacar, haja vista as mais diversas críticas e polêmicas, seu posicionamento no que se refere ao instituto da escravidão. Teixeira de Freitas era o que denominamos positivista romanista e, como tal,

Revista Brasileira de Direito Civil em Perspectiva | e-ISSN: 2526-0243 | Salvador | v. 4 | n. 1 | p. 18 - 38 | Jan/Jun. 2018 
considerava direito romano tudo aquilo que a sociedade romana considerava como sendo direito, ou seja, o jurista não permitia a interferência de juízos de valores que fossem capazes de distinguir o justo do injusto ou o verdadeiro do aparente. Nessa maneira, Teixeira de Freitas analisa a escravidão como entendia Bobbio (2006, p. 136) "um instituto jurídico como outro, mesmo que dela possa dar uma valoração negativa.”

A discussão sobre o instituto da escravidão não era comum durante o período de elaboração da Consolidação e do Esboço, nem mesmo a Constituição Imperial de 1824 não abordou o tema como sendo relevante, conforme se depreende do ensinamento de Rodrigues (1995, p. 159) "De fato, as referências à escravidão foram poucas e encontram-se diluídas nos anais da Assembléia, em meio às questões da organização administrativa e política que se encaminharam na Constituinte”.

Teixeira de Freitas não enaltece o instituto da escravidão, bem como não afirma expressamente ser contra o instituto, pois apenas o trata como qualquer outro instituto do direito romano, ou seja, afirma que se o instituto é adotado pela legislação deve ser respeitado e, nesse entendimento, o escravo não possui direitos, haja vista ser uma coisa, um bem. Teixeira de Fretas afirma que se o ordenamento jurídico quisesse, portanto, atribuir direitos aos escravos deveria abolir, extinguir a escravidão, mas, enquanto o instituto estiver em vigor não há falarse em direitos dos escravos, pois a Lei não lhes atribui a condição de pessoas.

Importante destacar que não houve abordagem do instituto da escravidão na Consolidação, Teixeira de Freitas optou por abordar o tema em legislação esparsa, fora do Código Civil, no que ele próprio denominou “Código Negro”, conforme se verifica na análise da própria obra de Freitas (2003, p. 37):

Cumpre advertir, que não há um só lugar do nosso texto, onde se trate de escravos. Temos, é verdade, a escravidão entre nós; mas esse mal é uma excepção, que lamentamos; condemnado á extinguir-se em época, mais, ou menos, remota; façamos também uma excepção, um capitulo avulso, na reforma das nossas Leis Civis; não as maculemos com disposições vergonhosas, que não podem servir para a posteridade: fique o estado de liberdade sem o seu correlativo odioso. As Leis concernentes á escravidão 
(que não são muitas) serão pois classificadas á parte, e formarão nosso Codigo Negro.

A principal discussão sobre o referido tema deu-se na aplicação do direito romano para os filhos de uma escrava que havia conseguido o "status" de liberdade, enfim, definir se os filhos de uma escrava, que em testamento havia sido libertada, com cláusula de servir a um herdeiro ou legatário enquanto este vivesse, seriam livres em razão do nascimento ou continuariam escravos. A posição de Teixeira de Freitas, Pena (2001, p. 114) foi conservadora e contrária à liberdade do interessado, opinião minoritária que entendia a escravidão como um fato: "existia como instituição legal e, apesar de 'macular' o País, deveria ser respeitada e garantida, porque a lei assim o estabelecia.”

Sobre o parecer de Teixeira de Freitas nesta discussão jurídica sobre a escravidão e o debate com Carlos Alberto Soares, é esclarecedora a lição de Meira (1979, p. 86):

Freitas, em seu parecer, concluía que os filhos, em tais condições, nasciam
escravos. Carlos Alberto Soares opinou em sentido contrário, isto é, que os
filhos nasciam livres. O plenário ficou com Alberto Soares, aprovando-lhe o
parecer, contra a opinião de Freitas. Este renuncia em longa carta, na qual
conclui, de maneira um pouco rude, oferecendo ao Instituto a pequena quantia
de 1:000\$000 para ser aplicada na fundação de sua Biblioteca, e
recomendando-vos, sobretudo, que a enriqueça com o Corpus Juris, que deve
ser a fonte vital, e onde devemos beber sempre e sem descanso

A posição de Teixeira de Freitas sobre a escravidão não foi isenta de críticas, entretanto, apesar da polêmica sobre sua posição em relação ao relevante tema, a importância de Teixeira de Freitas para a concretização do direito civil brasileiro, em especial pela Consolidação das Leis Civis e pelo “Esboço” do Código Civil, é ressaltada por Cruz (1981, p. 65) segundo o qual a Consolidação foi a obra mais respeitada na segunda metade do século XX, pois conseguiu impor na jurisprudência e na doutrina o prestígio da corrente conservadora, não permitindo que vários institutos do direito português, de correntes progressistas, não fossem aceitos no Brasil:

[...] a expressão mais autorizada do direito vigente no Brasil. Respeitada como um verdadeiro código, ela conseguiu impor, na jurisprudência e na doutrina, 
o prestígio da corrente conservadora, fazendo cair em desgraça, duma vez para sempre, várias inovações preconizadas pela corrente progressista, que o direito brasileiro, ao contrário do direito português, jamais aceitaria.

Nas palavras de Santos (2003, p. 360) Teixeira de Freitas era um “perfeito conhecedor de todo corpo do Direito Pátrio” considerado um “jurisconsulto filósofo”:

Despreocupado dos assuntos terrenais, pôde Teixeira de Freitas se debruçar
somente no profundo estudo do Direito, dando aportes claros sobre alguns
assuntos, a fim de que não pairassem dúvidas sobre a sua capacidade de
introjetar-se em si mesmo, dar um mergulho no seu âmago, ensimesmar-se e,
quando retornasse à tona, tivesse sempre um trabalho digno das letras jurídicas
nacionais. Em retiro, penetrava na meditação do Direito e assim permanecia.
Depois de dezoito anos dessa intensa e permanente meditação, conseguiu o
reconhecimento de seus pares como um grande advogado e jurista. Dezoito
anos bastaram para Teixeira de Freitas ouvir do grande jurisconsulto, o Barão
de Penedo, que ele - Teixeira de Freitas - era perfeito conhecedor de todo o
corpo do Direito pátrio, muito versado na jurisprudência dos tribunais,
seguríssimo em suas opiniões. Romanista profundo, foi considerado
jurisconsulto filósofo.

Na mesma linha de argumentação e resumindo o progresso intelectual de Teixeira de Freitas é Saldanha (1985, p. 247) segundo ao qual: "Freitas repensou continuamente os textos romanos, as classificações maiores, os conceitos de Savigny e de mais alguns grandes mestres, complementando os com o conhecimento de autores "menores", mas conservando-os à mão para reexames constantes.” Sobre as inovações e genuinidade do pensamento do jurista brasileiro o mesmo Saldanha (1985, p. 248) ainda preleciona: “A partir de um certo tempo já não acompanhou as novidades europeias; concentrou-se na revisão de suas obras, na reconstrução de sua vida profissional, no reexame dos problemas de sempre.”

É possível afirmar, portanto, que com as ideias originais de Teixeira de Freitas o direito civil brasileiro conseguiu o que Lima (1996, p. 159) denominava “emancipação intelectual”. Importante destacar que o Fundador da Nacionalidade Brasileira, título conferido a Oliveira 


\section{PENSAMENTO CIVIL BRASILEIRO: ANÁLISE DA GENUINIDADE DO DIREITO EM}

TEIXEIRA DE FREITAS

Lima, escrevia sobre a "emancipação" no sentido de evolução intelectual após a instalação da família real no Brasil, mas tal conceito pode ser utilizado ao referir-se a Teixeira de Freitas, pois da mesmo forma que a família real foi de fulcral importância para o desenvolvimento científico no Brasil, de maneira geral, Teixeira de Freitas foi de fundamental relevância para a consolidação e evolução de um direito civil de natureza brasileira.

Para arrematar o pensamento de Teixeira de Freitas, importante trazer à lume sua própria afirmação, (1952, p. 39) que foi expressa em nota de rodapé no art. 36 do “Esboço”: “(a)s leis são feitas para o homem, e não o homem para as leis. O homem é o ente inteligente e livre, e não uma tabula rasa em que o legislador constrói codificações arbitrárias.” Com esta frase confirma-se o pensamento inovador e atual do jurista brasileiro.

\section{CONSIDERAÇÕES FINAIS}

Assim, em razão do que se verificou na presente investigação, é possível afirmar que existe um pensamento civil brasileiro, ou seja, o ordenamento jurídico brasileiro, no âmbito do direito civil, não surge somente de institutos importados por juristas de outros países, é possível detectar originalidade de institutos do direito civil, que não só tem origem em solo e do pensamento de juristas brasileiro, mas que influenciaram outros países da América-Latina, na Europa e até mesmo em países de cultura jurídica oriental.

No pensamento de Teixeira de Freitas foi possível identificar diversos institutos com origem brasileira, com destaque para a unificação do direito privado, em que o jurista brasileiro afasta-se da tradicional de divisão entre direito civil e empresarial, tendência imposta pelo direito francês. Na mesma esfera, a divisão da codificação civil em parte geral e parte especial foi pensada incialmente por Teixeira de Freitas, sendo que tal afirmação ficou comprovada em razão da análise cronológica de sua exposição e a criação do Código Civil Alemão, que surge dez anos após o estudo do jurista brasileiro.

Ainda sobre as inovações no direito privado que tem origem no pensamento de Teixeira de Freitas, merece destaque a divisão do Código Civil em parte geral e parte especial, adotada dez anos depois pelo Bürgerliches Gesetzbuch - BGB e que serviu de orientação para as mais diversas legislações privadas do mundo moderno. Por fim, mas sem o intuito de esgotar as

Revista Brasileira de Direito Civil em Perspectiva | e-ISSN: 2526-0243 | Salvador | v. 4 | n. 1 | p. 18 - 38 | Jan/Jun. 2018 
afirmações sobre a genuinidade do pensamento de Teixeira de Freitas, a defesa de que os efeitos dos atos ilícitos seriam apenas os previstos em lei, é entendimento originário do jurista brasileiro, que só em 1967 foi adotado pelo Código Civil Português e depois por diversos outros ordenamentos jurídicos.

Por todos esses aspectos, e após análise da produção intelectual de Teixeira de Freitas, é possível concluir, que há ineditismo nas regras e princípios de direito privado em solo brasileiro, ou seja, a essência e a origem de diversos institutos do direito privado podem ser atribuídas a juristas brasileiros, a exemplo do jurista objeto desta pesquisa, que estabeleceram e assimilaram diversos institutos do direito civil, bem como deixaram como legado um raciocínio civilista eminentemente brasileiro.

\section{REFERENCIAS}

ALVES, José Carlos Moreira. Panorama do direito civil brasileiro: das origens aos dias atuais. Vol 88. São Paulo: Revista da Faculdade de Direito da Universidade de São Paulo. 1993;

BEVILÁQUA, Clóvis. Linhas e perfis jurídicos. Rio de Janeiro: Editora Freitas Bastos, 1930;

BOBBIO, Norberto. O positivismo jurídico: Lições de filosofia do Direito. Trad. e notas: Márcio Pugliesi, Edson Bini e Carlos E. Rodrigues. São Paulo: Ícone, 2006;

BRASIL. Constituição Politica do Imperio do Brazil (de 25 de março de 1824). Disponível em: http://www.planalto.gov.br/ccivil_03/Constituicao/Constituicao24.htm. Acesso em 10.06.2016 às 11h34min, horário de Brasília - Brasil;

CALMON, Pedro. A reforma da Universidade e os dois brasileiros que a planejaram, in: "Revista de História das Ideias - O Marquês de Pombal e o seu tempo". Tomo II, Coimbra: Instituto de História e Teoria das Ideias - Faculdade de Letra, 1982;

CÂMARA, José Gomes Bezerra. Subsídios para a História do Direito Pátrio. Rio de Janeiro: Livraria Brasiliana Editora, 1965.

CAPANEMA, Sylvio de Souza. A influência do Código Civil Francês no Direito Brasileiro. In: Revista da Emerj - Escola da Magistratura do Estado do Rio de Janeiro, v. 7, n. 26, 2004;

CASTRO, Anibal Pinto. Os poetas da Inconfidência, Escolares de Coimbra. In: "O iluminismo Luso-Brasileiro”, Academia das Ciências de Lisboa, Academia Brasileira de Letras. Lisboa: Imprensa Nacional-Casa da Moeda, 2007;

Revista Brasileira de Direito Civil em Perspectiva | e-ISSN: 2526-0243 | Salvador | v. 4 | n. 1 | p. 18 - 38 | Jan/Jun. 2018 
COGGIOLA, Oswaldo. Brasil: A questão agrária e a luta do MST. In: BARSOTTI, Paulo. PERICÁS, Luiz Bernardo (org.). América Latina: história, crise e movimento. São Paulo: Xamã, 1999;

CRUZ, Guilherme Braga da. Formação histórica do moderno Direito Privado português e brasileiro. In: Obras Esparsas II. Estudos de história do direito: direito moderno - $1^{\mathrm{a}}$ parte. Coimbra: Imprensa da Universidade, 1981.

DAVID, René. Les grands systèmes du droit contemporains. (droid compare). Tradução de Hermínio A. Carvalho. 2a ed. São Paulo: Martins Fontes. (Coleção Justiça e Direito), 2002;

FLEIUSS, Max. História Administrativa do Brasil. 2a ed. São Paulo: Companhia Editora Melhoramentos de São Paulo, 1925;

FREITAS, Augusto Teixeira de. Consolidação das leis civis. $3^{\mathrm{a}}$ ed. Rio de Janeiro: H. Garnier. 1896;

Augusto Teixeira de. Consolidação das leis civis. Prefácio de Ruy Rosado de Aguiar. Coleção história do direito brasileiro - Direito Civil, 2 Vol. Brasília: Senado Federal. Conselho Editorial, 2003;

Augusto Teixeira de. Codificação do Direito civil (carta de 20 de Setembro de 1867 ao Ministro da Justiça). Rio de Janeiro: Arquivo Nacional, 1977;

Augusto Teixeira de. Esboço. Rio de Janeiro: Ministério da Justiça, 1952;

FREITAS, Jordão de. A Expedição de Martin Afonso de Sousa, in: História da Colonização Portuguesa do Brasil, vol. III, Porto, 1924, p. 97.

GOMES, Orlando. Introdução ao direito civil. $20^{\mathrm{a}}$ ed., $2^{\mathrm{a}}$. tir., rev., atual. e aum., de acordo com o Código Civil de 2002, por Edvaldo Brito e Reginalda Paranhos de Brito. Rio de Janeiro: Forense, 2010;

GÓMEZ. J. Miguel Lobato. O Código Bicentenário. Revista da Emerj - Escola da Magistratura do

Estado do Rio de Janeiro, v. 7, n. 26, 2004;

LIBERATO, Ana Paula Gularte. Direito Humano Fundamental: A Reforma Agrária. Dissertação de Mestrado - PUCPR. Curitiba: PUCPR, 2003

LIMA, Manoel Oliveira. Dom João VI no Brasil. Rio de Janeiro: Topbooks, 1996;

MARCOS, Rui de Figueiredo; MATHIAS, Carlos Fernando e NORONHA, Ibsen. História do Direito Brasileiro. Rio de Janeiro: Forense, 2014; 
MEIRA, Silvio. Teixeira de Freitas - O Jurisconsulto do Império - Vida e Obra. Rio de Janeiro: José Olympio, 1979.

MEIRA, Sílvio. jurisconsulto brasileiro Augusto Teixeira de Freitas em face do direito universal. "In” SCHIPANI, Sandro (a cura di). Augusto Texeira de Freitas e il diritto latinoamericano. Roma: Padova: Cedam. 1983;

PONTES DE MIRANDA, Francisco Cavalcante. Tratado de Direito Privado - introdução, pessoas físicas, pessoas jurídicas I. Rio de Janeiro: Borsoi, 1954;

NASCIMENTO, Walter Vieira do. Lições de História do Direito. $11^{\mathrm{a}}$ ed. Rio de Janeiro: Forense, 1999;

NOGUEIRA, Almeida. A Academia de São Paulo - Tradições e Reminiscências. Vol I. São Paulo: Academia de São Paulo, 1953;

PENA, Eduardo Spiller. Pajens da casa imperial: jurisconsultos, escravidão e a Lei de 1871. Campinas: Editora Unicamp-Cecult, 2001. $1^{\text {a }}$ reimp, 2005;

PEDROSA, Ronaldo Leite. Direito em história. 5a ed. Rio de Janeiro: Lumem Juris, 2006;

PEREIRA, Caio Mário da Silva. Instituições de direito civil: introdução ao direito civil. Teoria geral do direito civil. Vol I. 26 a ed., rev. e atual. por Maria Celina Bodin de Moraes. Rio de Janeiro: Forense, 2013;

REALE, Miguel. Lições preliminares de Direito. 25ª ed. São Paulo: Saraiva, 2001;

RODRIGUES, Manuel Augusto. A Universidade de Coimbra e a elite intelectual brasileira na última fase do período colonial, in: “A Universidade de Coimbra. Figuras e factos de sua história”, Vol I, Porto: Campo da Letras. 2007;

RODRIGUES, Jaime. Liberdade, humanidade e propriedade: os escravos e a assembléia constituinte de 1823. Revista do Instituto de Estudos Brasileiros. v. 39. São Paulo: IEB, 1995; 
SALDANHA, Nelson Nogueira. Historia e sistema em Teixeira de Freitas. Revista de Informação Legislativa, A. 22, nº 85, Brasília: Senado Federal, 1985;

SILVA SANTOS, Antônio Jeová - Teixeira de Freitas Jurista inolvidável, in Grandes juristas brasileiros. São Paulo: Editora Martins Fontes, 2003;

VENOSA, Silvio de Salvo. Direito Civil. Vol I. 13ª ed. São Paulo: Atlas, 2013;

WALD, Arnoldo. A obra de Teixeira de Freitas e o Direito Latino-Americano. Brasília: Revista de Informação Legislativa ano. 41 n. 163 jul./set. 2004; 